\title{
Z-test for gender populations: knowledge analysis for environment
}

\section{Monika Raghuvanshið}

Pacific Academy of Higher Education and Research University, Udaipur, Rajasthan, India

D Corresponding author: M Raghuvanshi, E-mail: monikaraghuvanshi07@gmail.com Copyright (C2016 Raghuvanshi, This is an open access article published under the terms of the Creative Commons Attribution License, which permits unrestricted use, distribution, and reproduction in any medium, provided the original work is properly cited.

Preferred citation for this article: Raghuvanshi M. 2016. Z-test for gender populations: knowledge analysis for environment. Journal of Agriculture and Ecology, 1: 71-80; http://doi.org/10.53911/JAE.2016.1108.

\section{Abstract}

Environmental knowledge gives elemental practices and optimum utilization of resources. This gives a balanced surrounding with fulfillment of growing needs. This helps in repletion process. Gender based studies conducted have failed to reach a common conclusion. Hence this study was conducted to compare and measure the environmental knowledge of boys and girls. The city of Bikaner, Rajasthan was selected because it is located on the fringe of Thar desert making environment a very vital issue for the survival of the town. The study was conducted on youths of age group 14 to 20. Primary data was collected using pre-tested questionnaire. The study covered various aspects of environmental topics such as water, transportation, trees, air and global warming. To analyze difference in knowledge level of genders, chi-square or z-test were applied. Environmental knowledge index was calculated using cumulative scores and index number formula. The students were quite divided in their opinion on questions related to environmental topics such as water, transportation, trees and air. Some issues of the above mentioned topics raised no difference among the knowledge level of boys and girls where as in others differences crept. No significant differences in knowledge level of genders on global warming were observed. However, combined result showed girls seemed to possess more knowledge level with environmental knowledge index of 52.19 than boys of the same age group with a difference of 4.26. Environmental knowledge index was average hence students need to be informed more.

Key Words: Environmental knowledge, gender, knowledge index

\section{Introduction}

Environmental knowledge gives a survival point which can impart life giving techniques to the future generations. Environmental knowledge gives elemental practices nurtured by optimum utilization of natural resources. This creates balance in life of every individual practicing it and is a must in developing world where the pace of development is rapid to leave long lasting foot prints on the nature. Environmental knowledge regains balance of surroundings with satisfaction of veracious needs growing day by day and natural resources. So knowledge about environment can help to recover the required pace of repletion. 
Gender based studies conducted so far have generally found girls to be better associated with environment, boys to acquire more knowledge or no gender effect on knowledge. Hence, various studies have shown variable output as per place, so this study was conducted at Bikaner city. Along with this knowledge index, was also calculated to know the level of knowledge of both genders. The city of Bikaner was selected as it is located on the fringe of Thar Desert, making environment a very vital issue for the survival of the town. The main objectives of the study were to find out the difference in the environmental knowledge level of boys and girls as well as to calculate the environmental knowledge index of boys and girls.

\section{Materials and Methods}

The project was taken up in the secondary schools at Bikaner city. The target population comprised of youths of age group 14 to 20 as at this age they are matured enough to understand the questions and have studied environment in their course curriculum. Data and information were collected from the targeted respondents by using a pre-tested structured questionnaire. Students studying in various government and private secondary and senior secondary schools in the town formed the population of the study. A sample of 541 students was taken for the study by using a cluster sampling procedure. The hypothesis was categorized as $\mathrm{H}_{0}$ (No difference existed in the knowledge level of boys and girls) and $\mathrm{H}_{1}$ (Difference in the knowledge level of boys and girls existed). $\mathrm{Z}$ test for two populations, 1 for boys and 2 for girls was subjected to two tailed hypothesis at 5 percent level of significance. The following aspects were taken into consideration.

(1)Source of water-Canal

Individuals from sample population 1

104

Total sample population 1

150

Individuals from sample population 2

300

Total sample population 2

391

The Z-Score was -1.7701 . The p-value was 0.07672 . The proportion of 'Yes' response for observation 1 was 0.693 . The proportion for observation 2 was $0.767 . \mathrm{H}_{0}$ was accepted, as the difference in the knowledge levels of the boys and the girls was not significant.

(2.a) Cause of water pollution- Sewerage contamination with water.

Individuals from sample population 1

30

Total sample population 1

150

Individuals from sample population 2

183 
Total sample population 2

391

The Z-Score was -5.712 and the p-value was 0. The proportion of 'Yes' response for observation 1 was 0.2 . The proportion for observation 2 was $0.468 . \mathrm{H}_{0}$ was rejected, means that the difference in the knowledge levels of the boys and the girls was significant.

(2.b) Cause of water pollution- Effluents from industries.

Individuals from sample population 1

97

Total sample population 1

150

Individuals from sample population 2

293

Total sample population 2

391

The Z-Score was -2.3837 and the p-value was 0.01732 . The proportion of 'Yes' response for observation 1 was 0.647 . The proportion for observation 2 was $0.749 . \mathrm{H}_{0}$ was rejected, means that the difference in the knowledge levels of the boys and the girls was significant.

(2.c) Cause of water pollution- Pesticides.

Individuals from sample population 1

65

Total sample population 1

150

Individuals from sample population 2

177

Total sample population 2

391

The Z-Score was -0.4052 while the p-value was 0.6818 . The proportion of 'Yes' response for observation 1 was 0.433 . The proportion for observation 2 was 0.453 . The $\mathrm{H}_{0}$ was accepted, as the difference in the knowledge level of the boys and the girls was not significant.

(2.d) Cause of water pollution- Salts in ground water.

Individuals from sample population 1

42

Total sample population 1

150

Individuals from sample population 2

110

Total sample population 2

391 
The Z-Score was -0.0308 . The p-value was 0.97606 . The proportion of 'Yes' response for observation 1 was 0.28 . The proportion for observation 2 was 0.281 . Here, $\mathrm{H}_{0}$ was accepted. (3.a) Cause of air pollution- Public vehicles.

Individuals from sample population 1

99

Total sample population 1

150

Individuals from sample population 2

238

Total sample population 2

391

The Z-Score was 1.1022. The p-value was 0.27134 . The proportion of 'Yes' response for observation 1 was 0.66 . The proportion for observation 2 was 0.609 . The $\mathrm{H}_{0}$ was accepted, means that the difference in the knowledge levels of the boys and the girls was not significant.

(3.b) Cause of air pollution- Autos.

Individuals from sample population 1

45

Total sample population 1

150

Individuals from sample population 2

142

Total sample population 2

391

The Z-Score was -1.383. The p-value was 0.16758. The proportion of 'Yes' response for observation 1 was 0.3 . The proportion for observation 2 was 0.363 . The $\mathrm{H}_{0}$ was accepted, means that the difference in the knowledge levels of the boys and the girls was not significant.

(3.c) Cause of air pollution- Private vehicles.

Individuals from sample population 1

44

Total sample population 1

150

Individuals from sample population 2

162

Total sample population 2

391 
The Z-Score was -2.5943. The p-value was 0.0096. The proportion of 'Yes' response for observation 1 was 0.293 . The proportion for observation 2 was 0.414 . The $\mathrm{H}_{0}$ was rejected, means that the difference in the knowledge level of the boys and the girls was significant.

(3.d) Cause of air pollution- Factories.

Individuals from sample population 1

98

Total sample population 1

150

Individuals from sample population 2

298

Total sample population 2

391

The Z-Score was -2.5579. The p-value was 0.01046. The proportion of 'Yes' response for observation 1 was 0.653 . The proportion for observation 2 was 0.762 . The $\mathrm{H}_{0}$ was rejected, means that the difference in the knowledge levels of the boys and the girls was significant.

(3.e) Cause of air pollution- Burning of garbage

Individuals from sample population 1

122

Total sample population 1

150

Individuals from sample population 2

339

Total sample population 2

391

The Z-Score was -1.5744 and p-value was 0.11642 . The proportion of 'Yes' response for observation 1 was 0.813 . The proportion for observation 2 was $0.867 . \mathrm{H}_{0}$ was accepted, means that the difference in the knowledge levels of the boys and the girls was not significant.

(4.a) Tree plantation- Forest department

Individuals from sample population 1

78

Total sample population 1

150

Individuals from sample population 2

245

Total sample population 2

391 
The Z-Score was -2.2628. The p-value was 0.02382. The proportion of 'Yes' response for observation 1 was 0.52 . The proportion for observation 2 was $0.627 . \mathrm{H}_{0}$ was rejected, means that the difference in the knowledge levels of the boys and the girls was significant.

(4.b) Tree plantation- Municipal Corporation

Individuals from sample population 1

33

Total sample population 1

150

Individuals from sample population 2

85

Total sample population 2

391

The Z-Score was 0.0658. The p-value was 0.9442. The proportion of 'Yes' response for observation 1 was 0.22 . The proportion for observation 2 was 0.217 . $\mathrm{H}_{0}$ was accepted, means that the difference in the knowledge levels of the boys and the girls was not significant.

(4.c) Tree plantation- Corporate entities

Individuals from sample population 1

21

Total sample population 1

150

Individuals from sample population 2

40

Total sample population 2

391

The Z-Score was 1.241. The p-value was 0.21498 . The proportion of 'Yes' response for observation 1 was 0.14 . The proportion for observation 2 was $0.102 . \mathrm{H}_{0}$ was accepted.

(4.d) Tree plantation- NGOs (Non-governmental organizations)

Individuals from sample population 1

35

Total sample population 1

150

Individuals from sample population 2

58

Total sample population 2

391

The Z-Score was 2.3456. The p-value was 0.01878. The proportion of 'Yes' response for observation 1 was 0.233 . The proportion for observation 2 was 0.148 . $\mathrm{H}_{0}$ was rejected, as significant difference existed in the knowledge levels of the boys and the girls. 
(4.e) Tree plantation- At an individual level

Individuals from sample population 1

117

Total sample population 1

150

Individuals from sample population 2

321

Total sample population 2

391

The Z-Score was -1.0866. The p-value was 0.27572. The proportion of 'Yes' response for observation 1 was 0.78 . The proportion for observation 2 was $0.821 . \mathrm{H}_{0}$ was accepted.

(5.a) Global warming- Rise in temperature.

Individuals from sample population 1

99

Total sample population 1

150

Individuals from sample population 2

257

Total sample population 2

391

The Z-Score was 0.0595. The p-value was 0.95216. The proportion of 'Yes' response for observation 1 was 0.66 . The proportion for observation 2 was $0.657 . \mathrm{H}_{0}$ was accepted.

(5.b) Global warming- Melting of glaciers

Individuals from sample population 1

73

Total sample population 1

150

Individuals from sample population 2

177

Total sample population 2

391

The Z-Score was 0.7097 . The p-value was 0.4777 . The proportion of 'Yes' response for observation 1 was 0.487 . The proportion for observation 2 was $0.453 . \mathrm{H}_{0}$ was accepted.

(5.c) Global warming- Disturbed weather cycle

Individuals from sample Population 1

88

Total sample Population 1

150 
Individuals from sample Population 2

228

Total sample Population 2

391

The Z-Score was 0.0749 . The p-value was 0.9442 . The proportion of 'Yes' response for observation 1 was 0.587 . The proportion for observation 2 was $0.583 . \mathrm{H}_{0}$ was accepted, means that the difference in the knowledge levels of the boys and the girls was not significant.

(5.d) Global warming- Disturbed eco-system

Individuals from sample Population 1

76

Total sample Population 1

150

Individuals from sample Population 2

224

Total sample Population 2

391

The Z-Score was -1.3873 . The p-value was 0.16452. The proportion of 'Yes' response for observation 1 was 0.507 . The proportion for observation 2 was $0.573 . \mathrm{H}_{0}$ was accepted, means that the difference in the knowledge level of the boys and the girls was not significant.

Environmental knowledge index (EKI)

Environmental knowledge Index $(\mathrm{EKI})=\left[\left\{\left(\sum\right.\right.\right.$ Scores for different items $) \div$ Number of respondents $\} \div$ Number of questions $] \times 100$

(Here "no response" has been counted as "no knowledge")

EKI $_{\text {Boys }}=\{(104+30+97+65+42+99+45+44+98+122+78+33+21+35+117+99+73+88+76) \div$ $150\} \div 19\} \times 100$

$=1366 / 150$

$=9.1067 / 19$

$=0.4793 * 100$

$=47.93$

EKI $_{\text {Girls }}=\{\{(300+183+293+177+110+238+142+162+298+339+245+85+40+58+321+257+$

$177+228+224) \div 391\} \div 19\} \times 100$

$=3877 / 391$

$=9.9156 / 19$

$=0.5219 * 100$

$=52.19$

Comparison between the indices shows that the level of knowledge towards environment was higher among the girls as compared to boys.

To conclude we have jotted down the questionnaire and the existing gap between the knowledge level of the boys and the girls of the drawn sample. 


\begin{tabular}{|c|c|c|}
\hline $\mathrm{T}$ & Question & $\begin{array}{l}\text { Analysis shows that the difference in the } \\
\text { knowledge levels of the boys and the girls }\end{array}$ \\
\hline 1 & Source of water & \\
\hline $1 \mathrm{a}$ & Canal & Not significant \\
\hline 2 & Cause of water pollution & \\
\hline $2 \mathrm{a}$ & $\begin{array}{l}\text { Sewerage contamination in } \\
\text { water }\end{array}$ & Significant \\
\hline $2 b$ & Effluents from industries & Significant \\
\hline $2 c$ & Pesticides & Not significant \\
\hline $2 d$ & Salts in ground water & Not significant \\
\hline 3 & Cause of air pollution & \\
\hline $3 a$ & Public vehicles & Not significant \\
\hline $3 b$ & Autos & Not significant \\
\hline $3 c$ & Private vehicles & Significant \\
\hline $3 d$ & Factories & Significant \\
\hline $3 e$ & Burning of garbage & Not significant \\
\hline 4 & Tree plantation & \\
\hline $4 a$ & Forest department & Significant \\
\hline $4 b$ & Municipal corporation & Not significant \\
\hline $4 c$ & Corporate entities & Not Significant \\
\hline $4 d$ & NGOs & Significant \\
\hline $4 \mathrm{e}$ & Each individual & Not significant \\
\hline 5 & Global warming & \\
\hline $5 a$ & Rise in temperature of earth & Not significant \\
\hline $5 b$ & Melting of glaciers & Not significant \\
\hline $5 c$ & Disturbed weather cycle & Not significant \\
\hline $5 d$ & Disturbed eco-system & Not significant \\
\hline
\end{tabular}

There lies a significant difference of 4.26 in environmental knowledge index of girls when compared to boys of the same age group.

The summary of the results can be drawn as better environmental knowledge of the girls in comparison to the boys of the same age group.

Studies conducted so far have shown variance in the knowledge level of boys and girls related to environment (Tikka et al. 2000), many studies have shown male students scored higher on knowledge scale as compared to females Hampel et al. (1996) and Gambro \& Switzky (1999). However many studies have shown no variance in the knowledge level of boys and girls (Alp et al. 2006). This shows difference in the knowledge level of boys and girls depend upon the type of questions asked.

Same kind of results were obtained during Z-test analysis carried topic-wise in which there was difference in the knowledge level of boys and girls in some topics however no difference in some topics but overall result shows girls seem to possess more knowledge as compared to boys, hence gender influence can be seen on knowledge about environmental issues. 
From our study, we enlist a series of suggestions which may help to close the gap among the boys and girls regarding environmental awareness.

a. A knowledge index of 48(app.) and 52(app.) is average hence students need to be informed more about environment.

b. Students should be made to understand importance of environment so that they start protecting it for their future.

c. Students should be guided on practical application of environmental education studied in curriculum.

d. If students are trained on eco-friendly practices, repletion is possible.

\section{References}

Alp E, Ertepinar H, Tekkaya C, \& Yilmaz A. 2006. A study on children's environmental knowledge and attitudes: The effect of grade level and gender. International Research in Geographical and Environmental Education, 15, 210-223.

Gambro JS \& Switzky HN. 1999. Variables associated with American high school students' knowledge of environmental issues related to energy and pollution. Journal of Environmental Education, 30 (2), 15-22.

Hampel B, Boldero J \& Holdsworth R. 1996. Gender patterns in environmental consciousness among adolescents. Australian and New Zealand Journal of Sociology, 32 (1): 58-71.

Tikka PM, Kuitunen MT, \& Tynys SM. 2000. Effects of educational background on students' attitudes, activity levels, and knowledge concerning the environment. The Journal of Environmental Education, 31(3): 12-19. 